\title{
EFFECT OF PRESS DISPLACEMENT ON IMPREGNATION PROPERTIES IN MELTED THERMOPLASTIC-RESIN TRANSFER MOLDING OF CONTINUOUS FIBER REINFORCED THERMOPLASTIC COMPOSITES
}

\author{
KAZUTO TANAKA, MOMOKA ASANO, TSUTAO KATAYAMA \& MASATAKA KAWAGUCHI \\ Department of Biomedical Engineering, Doshisha University, Japan
}

\begin{abstract}
The use of fiber reinforced thermoplastics (FRTP), which has high specific strength and specific stiffness, and excellent productivity and recyclability, is expected for weight reduction of the automotive body. Structural components made of continuous fiber reinforced thermoplastic composites with excellent mechanical properties are usually manufactured by secondary processing using laminated composites of fabrics which are pre-impregnated with thermoplastics. Since this method uses high-cost intermediate materials, development of a low-cost molding method is needed. A melted thermoplastic-resin transfer molding (MT-RTM) method in which a dry fabric of continuous fiber is impregnated with melted thermoplastic using an injection-press hybrid molding machine, has been developed. In this method, to impregnate continuous fibers with matrix resin is a key technology. In this study, GF/PA6 products with different press displacement after resin injection were molded by MT-RTM, and the cross-sectional observation and tensile test of the molded product were conducted to clarify the effect of press displacement on resin impregnation. When the amount of press displacement after injection is small, the ratio of the injected resin layer becomes large, and impregnation into continuous fibers becomes insufficient. In order to produce a molded product with a low voids content without forming a resin layer, it is necessary to maintain the press displacement after injection.
\end{abstract}

Keywords: FRTP, continuous fibers, impregnation, viscosity, melted thermoplastic-resin transfer molding, press displacement.

\section{INTRODUCTION}

Recently, in the automotive industry, where weight reduction of the body is indispensable in response to environmental issues, application of materials using composite materials is expected, and the development of a highly efficient molding method for mass production is required [1]-[3]. Compared to FRP using thermosetting resin as matrix, fiber reinforced thermoplastics (FRTP) is superior in productivity and recyclability, and its usage is expected. Continuous fiber reinforced composite materials with excellent mechanical properties such as high specific strength and high specific stiffness are generally subjected to secondary molding using a prepreg in which the fabric is impregnated with a thermoplastic resin in advance. Since this molding method uses the prepreg, a high-cost intermediate material, the development of a low cost FRTP molding method is expected [4], [5].

Carbon fiber reinforced thermosetting plastics (CFRTS), which uses a thermosetting resin as a matrix, is mainly used for aerospace applications, in which a prepreg is used and molded in an autoclave. On the other hand, for automotive applications, resin transfer molding (RTM), in which resin is impregnated into dry-type reinforcing fabrics, is used to offer affordable prices. We have been developing an melted thermoplastic-resin transfer molding (MT-RTM) method in which melted thermoplastic resin is injected and impregnated to continuous reinforcing fabrics using an injection-press hybrid molding machine [6]. In this study, we have clarified the effects of mold temperature and pressure holding time on the 
impregnation of continuous fibers using plain woven fabric of glass fiber as reinforcement and PA6 as matrix resin. In this molding method, it is important to impregnate the continuous fiber with resin, and FRTP in which the fibers are well impregnated with resin can be molded by setting the mold temperature near the melting point and maintaining enough pressure. In this study, GF/PA6 molded products with different press displacement after injection were molded by MT-RTM, cross-section observation of the molded products and tensile tests were performed, and the effect of the press displacement after injection on resin impregnation was clarified.

\section{MATERIALS AND EXPERIMENTAL METHODS}

\subsection{Materials}

Plain woven fabric of glass fiber (Nittobo, WFA230-100BS6, laminated configuration $\left(0^{\circ} / 90^{\circ}\right)$, basis weight $\left.200 \mathrm{~g} / \mathrm{m}^{2}\right)$ was used as the reinforcement, and injection pellets of polyamide 6 (PA6, Ube Industries, $1015 \mathrm{~B}$, melting point $226.5^{\circ} \mathrm{C}$ ) were used as the matrix resin.

\subsection{Molding method}

The press and injection hybrid molding machine (Satoh Group Co., LTD., STIP05-05) was used for MT-RTM. The schematic drawing of the MT-RTM process is shown in Fig. 1. After preheating the plain woven fabrics of glass fiber in the opened mold, the melted PA6 resin is injected; and the mold is closed and pressed to obtain a high-strength, high-rigidity and complex-shaped FRTP in $160 \mathrm{~mm} \times 240 \mathrm{~mm} \times 40 \mathrm{~mm}$ with a shell part reinforced with plain woven fabric of glass fiber, a rib part made of injected resin, and a flange part made of injected resin, as shown in Fig. 2. The barrel temperature of the injection molding machine is $280^{\circ} \mathrm{C}$, the injection pressure is $120 \mathrm{MPa}$, the injection speed is $150 \times 10^{-6} \mathrm{~m}^{3} / \mathrm{s}$, the press pressure is $5 \mathrm{MPa}$, the pressure holding time is $30 \mathrm{~s}$, and the mold temperature is $200^{\circ} \mathrm{C}$. After preheating the plain woven fabrics of glass fiber $\left(0^{\circ} / 90^{\circ}\right) 5 \mathrm{~s}$ for $90 \mathrm{~s}$, the mold opening amount was set for $2.8 \mathrm{~mm}, 4.8 \mathrm{~mm}$ and $8.8 \mathrm{~mm}$ [6] and press to $2.8 \mathrm{~mm}$ after resin injection. The products molded in this way are referred to as IP2, IP4, and IP8, respectively. For the sake of comparison, some products were molded without press pressure after resin injection. These are referred to as I2, I4, and I8, respectively. The amount of resin is controlled to obtain the fiber volume fraction of $40 \%$ for the shell part, and to fill the rib and the flange part with the injection resin.

\subsection{Evaluation of impregnation and mechanical properties}

In order to evaluate the impregnation property of the injected resin into the plain woven fabric of glass fiber within the shell, the thickness of the shell of molded products (IP2, IP4 and IP8) was measured. The cross section of the shell was finished with diamond paste and observed using a digital microscope (Keyence, VHX-5000) and a scanning electron microscope (JEOL, SEM, JSM-6390LT). In addition, the voids content was measured by considering the hollows as voids from the cross-sectional images observed with a confocal microscope (Lasertec, OPTEELICS H1200). The mechanical properties of the molded product were measured on specimens cut out from the shell into $180 \mathrm{~mm} \times 15 \mathrm{~mm}$ as shown in Fig. 3. Tensile tests were conducted by a universal precision testing machine (Shimadzu Corporation, Autograph AG-100 kN); at a displacement speed of $1.7 \times 10-5 \mathrm{~m} / \mathrm{s}(1 \mathrm{~mm} / \mathrm{min})$. Aluminum tabs were attached to both ends of the specimen using an epoxy adhesive. 
(a)

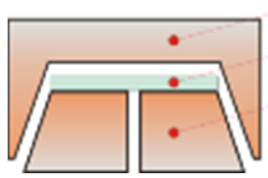

Cavity(Upper mold)

Dry fabric

Core(Lower mold)

(b)

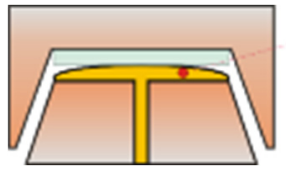

Resin

(c)

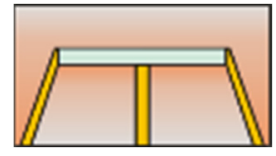

(d)

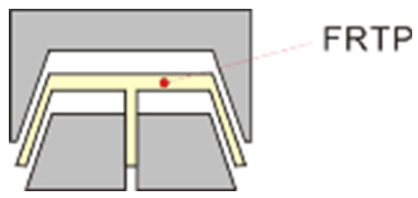

Figure 1: Schematic drawing of melted thermoplastic-resin transfer molding (MT-RTM) process. (a) Preheat; (b) Injection; (c) Press; and (d) Cooling and mold release.

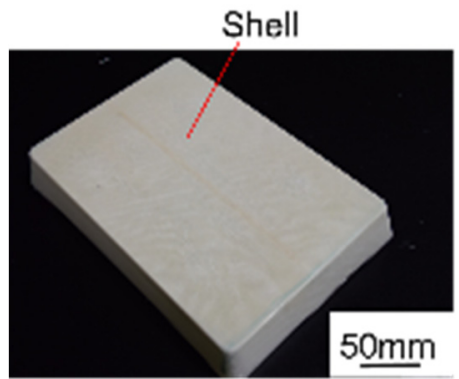

(a)

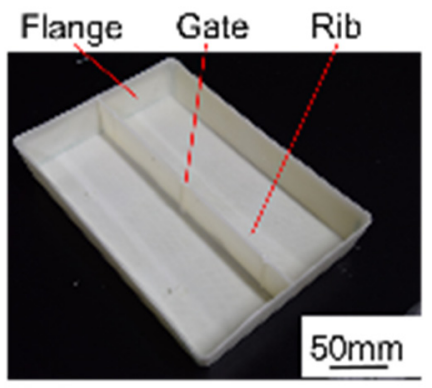

(b)

Figure 2: Molded product by MT-RTM. (a) Cavity side; and (b) Core side. 

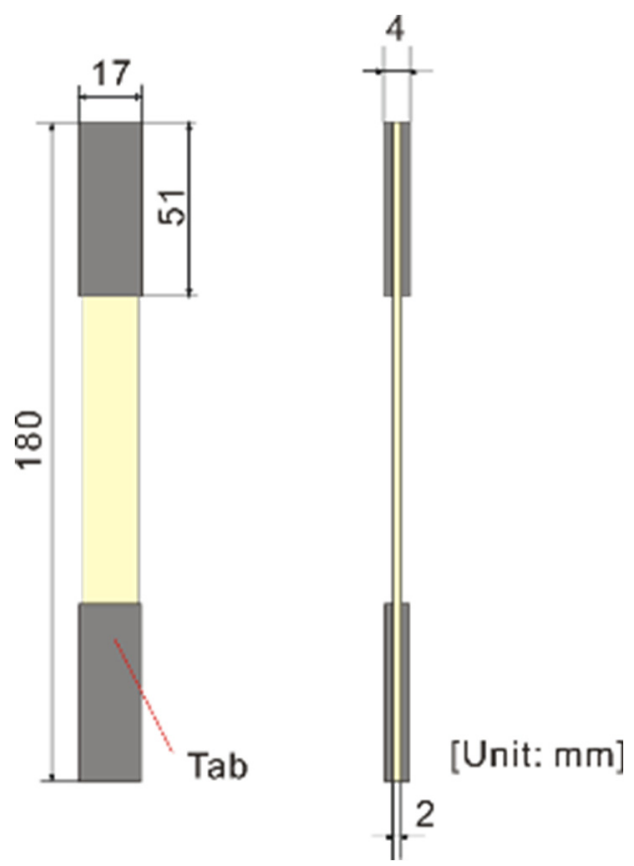

Figure 3: Schematic drawing of tensile test specimen.

\section{EXPERIMENTAL RESULTS AND DISCUSSION}

\subsection{Impregnation properties}

Fig. 4 shows the results of macro observations of the molded products of I2, I4 and I8, which were molded without press after resin injection with the mold opening amounts of $2.8 \mathrm{~mm}, 4.8 \mathrm{~mm}$ and $8.8 \mathrm{~mm}$ respectively. Fig. 5 shows the schematic drawing of the injected resin for I 2 and I8. The molded product of IP2, IP4 and IP8, which were pressed after resin injection were also shown in Fig. 4. In the case of I2 and IP2 shown in Fig. 4(a), and I4 and IP4 shown in Fig. 4(b), the resin was filled into the rib and flange part during injection process (Fig. 5(a)) and resin leaked. Some part of the plain woven fabric was impregnated with injected resin and the flange was curved. Although the resin was impregnated into the plain woven fabric of glass fiber by press process, the molded product had spotted patterns, indicating that the impregnation into the plain woven fabric of glass fiber was uneven. On the other hand, in the case of I8 and IP8 shown in Fig. 4(c), resin flow to the ribs and flanges by injection process is small, and most of the injected resin accumulates in the shell close to the injection gate (Fig. 5(b)). Furthermore, the resin was uniformly impregnated into the plain woven fabric while filling the rib and flange part with the press process. Fig. 6 shows the cross-sectional view of shell part observed by the digital microscope. In IP2 and IP4, the plain woven fabric of glass fiber was offset to the cavity side (upper) and the resin layer was formed on the core side (lower) where the injection gate was located. However, in case of IP8, the resin layer was not observed and the entire plain woven fabric is uniformly impregnated with resin. 


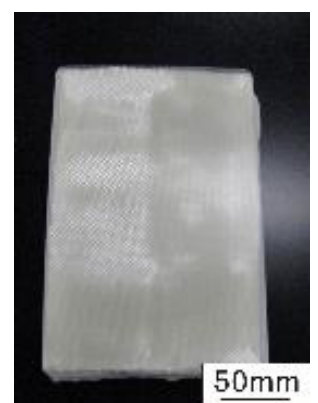

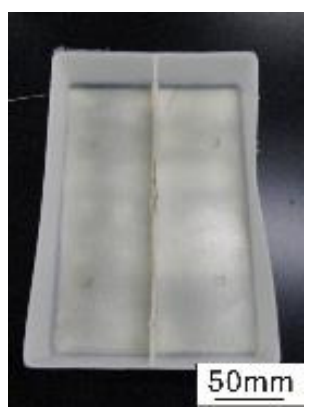

(i) I2

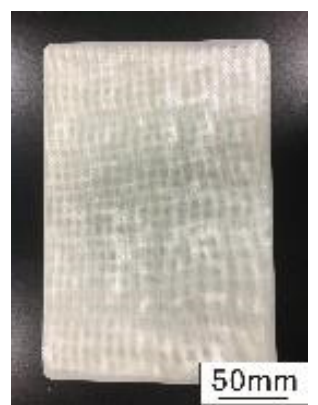

(ii) IP2

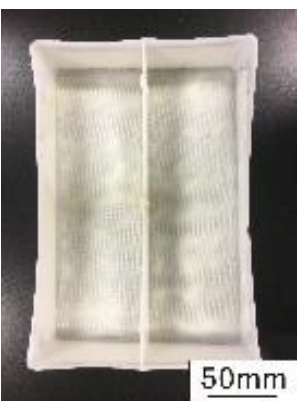

(a)
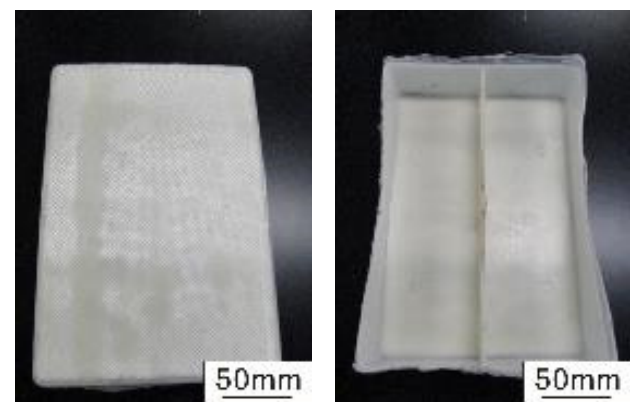

(i) I4
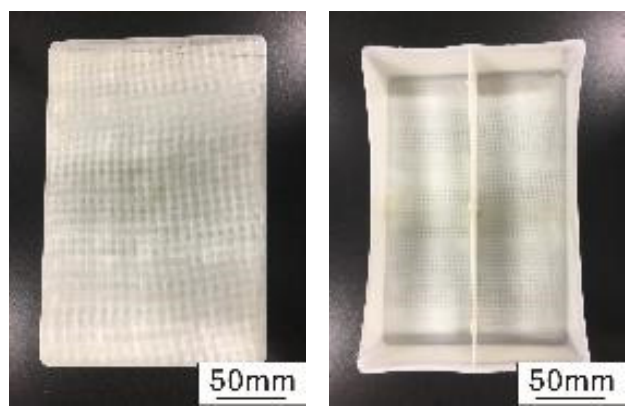

(ii) IP4

(b)
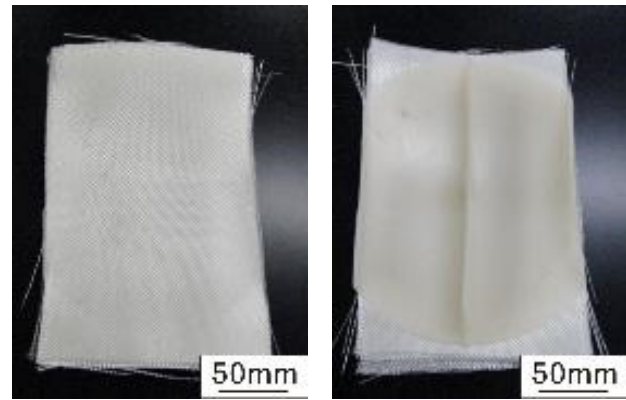

(i) I8
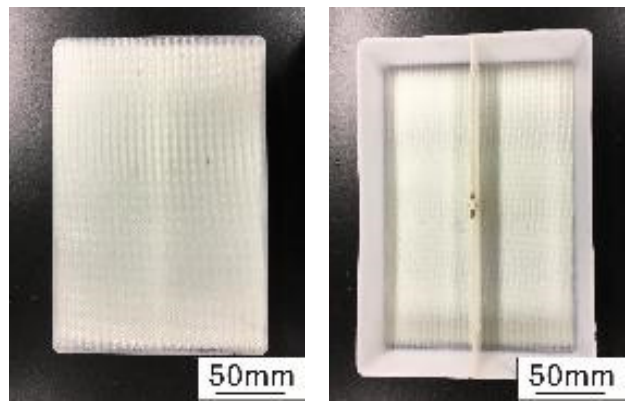

(ii) IP8

(c)

Figure 4: MT-RTM products molded at different mold opening amounts. (a) Mold opening amount $2.8 \mathrm{~mm}$; (b) Mold opening amount $4.8 \mathrm{~mm}$; and (c) Mold opening amount $8.8 \mathrm{~mm}$.

Fig. 7 shows the thickness of the shell part of the molded product. In the case of IP2, the thickness was small due to the resin leakage out of the mold before the fabric was impregnated with the resin. On the other hand, for IP4 and IP8, the fabric was impregnated with resin; the thickness is close to the designed thickness of $2 \mathrm{~mm}$. Fig. 8 shows the cross-sectional view of the central part of shell for the molded product. Many voids can be observed in the fiber bundle of IP2 and IP4, whereas in IP8 large voids cannot be observed. 
(a)

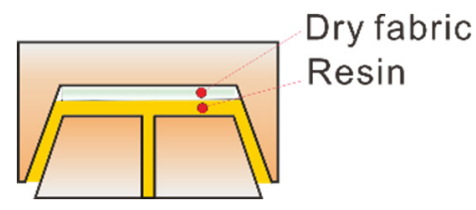

(b)

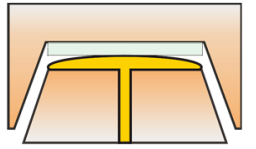

Figure 5: Schematic drawing of the injected resin for the I2 and I8. (a) I2; and (b) I8.

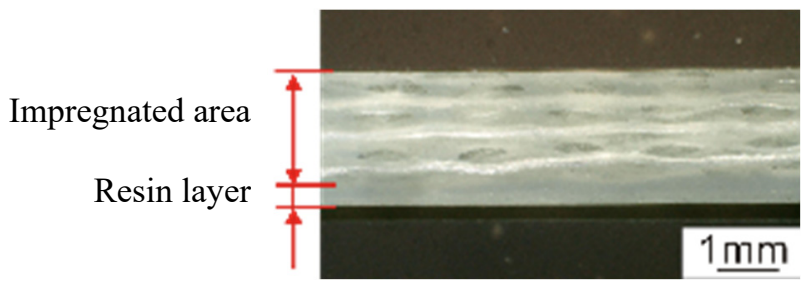

(a)

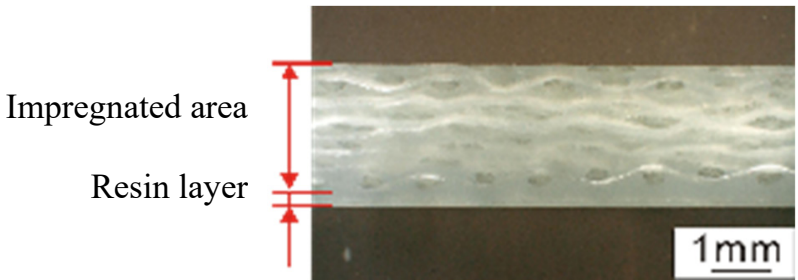

(b)

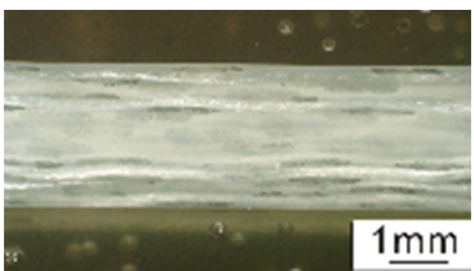

(c)

Figure 6: Digital microscopic observation of cross section of shell parts of MT-RTM products molded at different mold opening amounts. (a) IP2; (b) IP4; and (c) IP8.

Fig. 9 shows the voids content of shell obtained by the confocal microscope. For IP2 and IP4, the voids content was high and showed large variations. On the other hand, in case of IP8, the voids content was low and showed small variations. It has been reported that the 


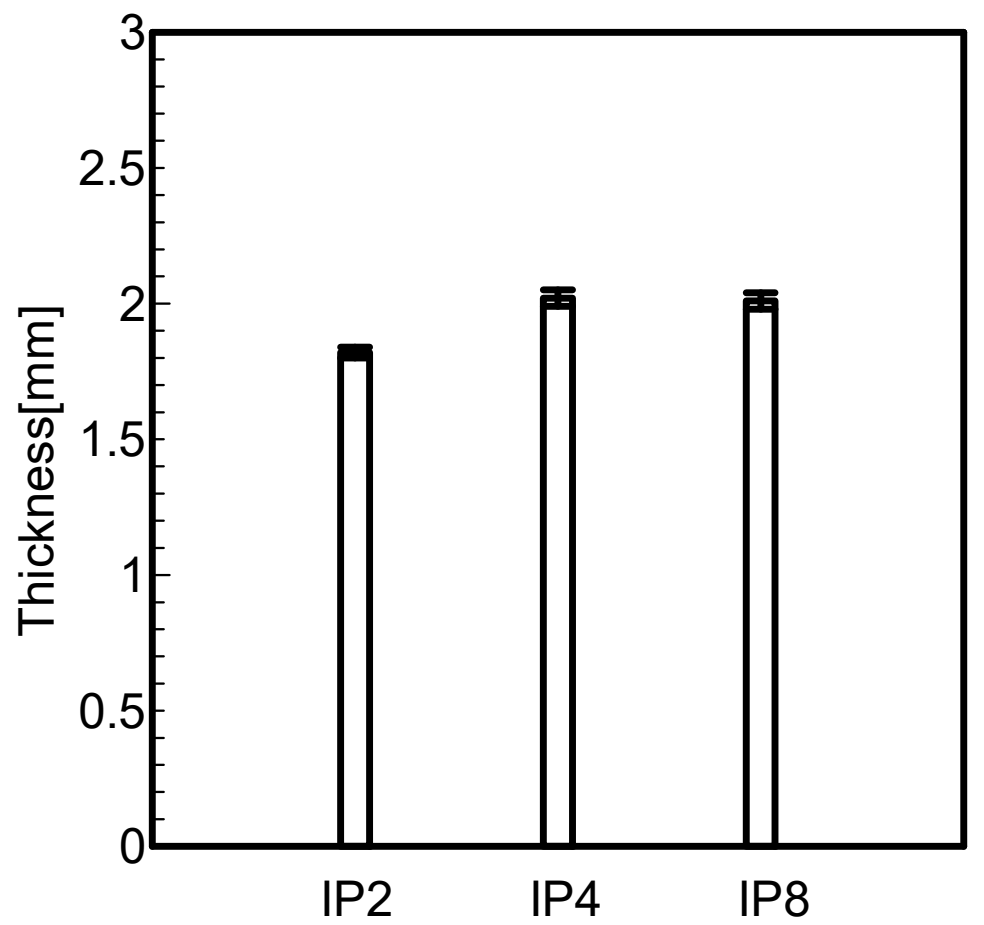

Figure 7: Thickness of shell parts of MT-RTM products.

lower the viscosity of the resin, the higher the impregnation into the reinforcing fibers for FRTP [7].

For IP8 as shown in Fig. 4, most of the resin accumulates in the shell when injection completed, resulting a thick core layer. Due to this high temperature and low viscosity of the injection resin in the shell, the plain woven fabric is considered to be uniformly impregnated by following press process and has a low voids content.

On the other hand, in case of IP2 and IP4, as the resin was filled into the ribs and flanges when injection was completed, the proportion of the skin layer of shell was large, and the viscosity increased due to the decreasing temperature of the resin. Hence, the impregnation is considered to be uneven and the voids content became high.

\subsection{Mechanical property}

Fig. 10 shows the tensile strength of the shell part for the molded product. IP8, molded products with larger press displacement shows higher tensile strength. In FRP, it has been reported that the lower the voids content, the higher the tensile strength [8]. In this study, IP8 showed low voids content and high tensile strength because the plain woven fabric of glass fiber was well impregnated with resin due to the larger press displacement. On the other hand, IP2 was considered to have low tensile strength due to the high voids content.

In MT-RTM process proposed in this study, the press displacement after injection is important since the plain woven fabric will be impregnated with the resin, that is accumulated in the shell close to the central gate. 
76 High Performance and Optimum Design of Structures and Materials IV

(a)

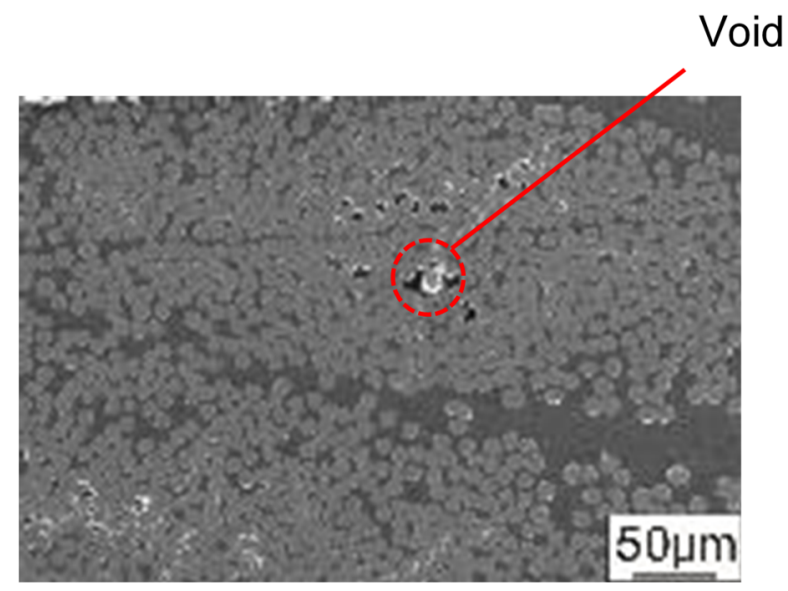

(b)

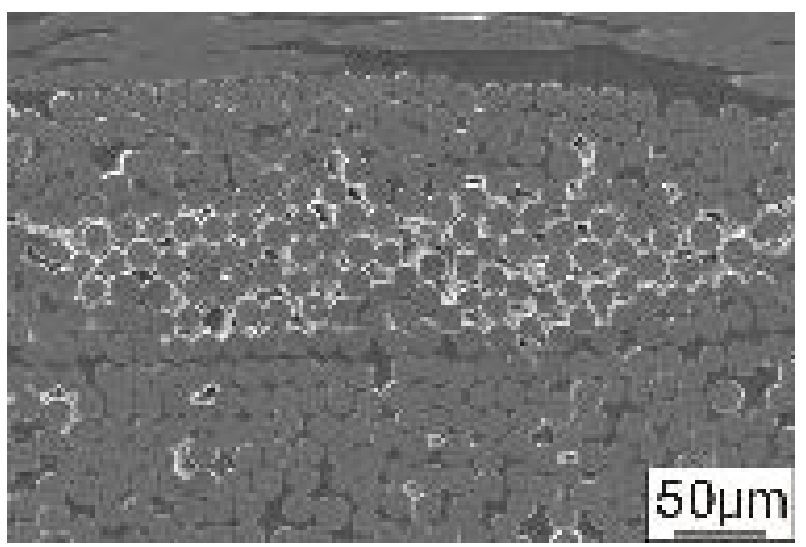

(c)

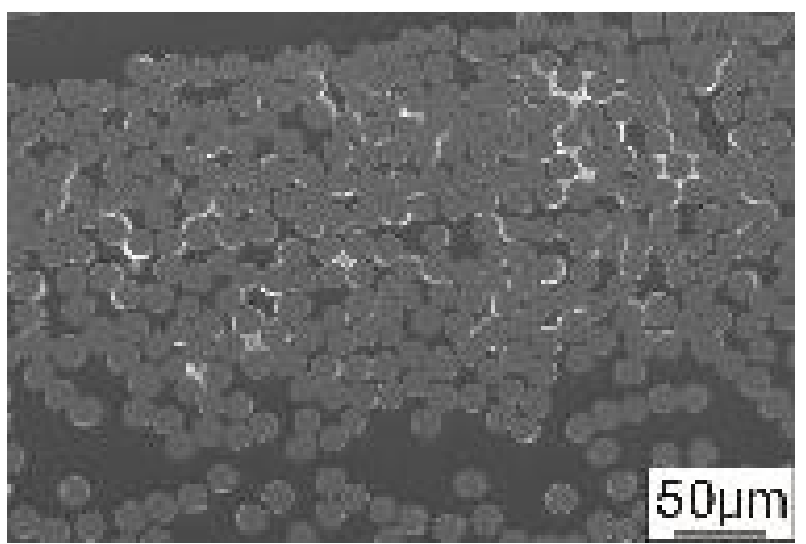

Figure 8: SEM observation of cross-sectional view of shell parts of MT-RTM products molded at different mold opening amounts. (a) IP2; (b) IP4; and (c) IP8. 


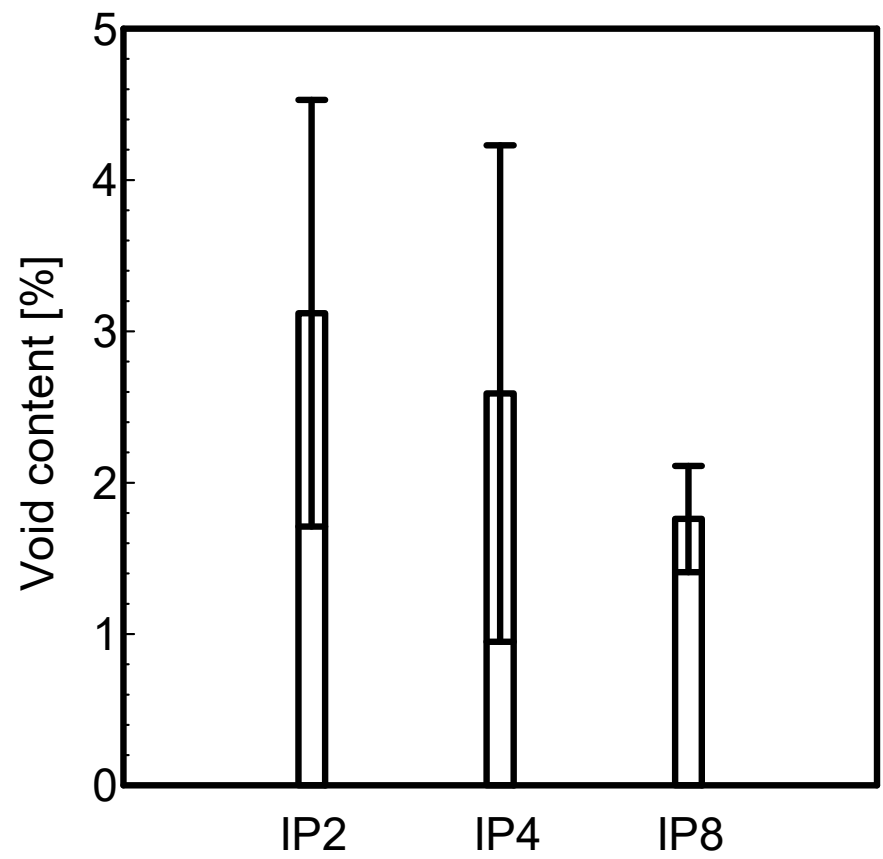

Figure 9: Voids content of shell parts of MT-RTM products.

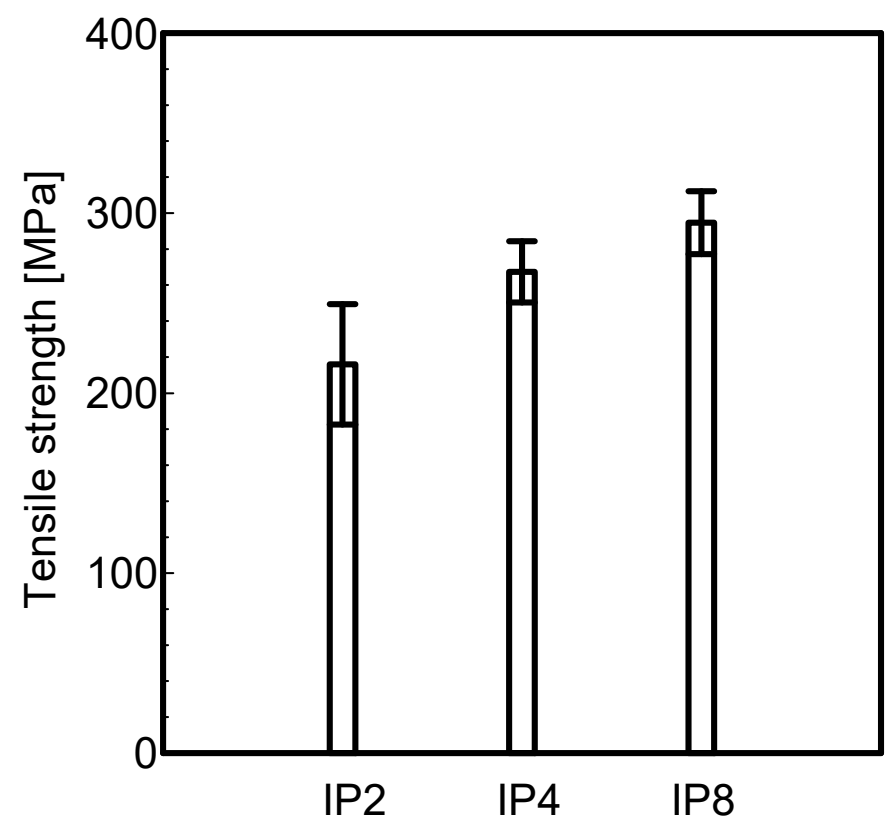

Figure 10: Tensile strength of shell parts of MT-RTM products. 


\section{CONCLUSION}

GF/PA6 molded products with different press displacement after resin injection were molded in Melted Thermoplastic-Resin Transfer Molding (MT-RTM). Cross-sectional observation of the molded products and tensile tests were performed. The investigation yielded the following conclusions:

1. In the case of larger press displacement after injection, resin impregnates the plain woven fabric uniformly and the molded products with lower void content and higher tensile strength can be obtained since the resin accumulated in the shell close to the central gate with high-temperature and low-viscosity state.

2. In the case of smaller press displacement after injection, the impregnation into the plain woven fabric becomes poor due to the higher viscosity of the resin which was filled into the ribs and flanges during injection process, and the voids content became high.

\section{REFERENCES}

[1] Horizono, H., Kanemasu, M., Hattori, H., Akiyama, H. \& Takayanagi, T., High efficient RTM development for thick and large composite parts. Mitsubishi Heavy Industries Technical Report, 48(4), pp. 56-61, 2011.

[2] Ishikawa, T., Overview of carbon fiber reinforced composites (CFRP) applications to automotive structural parts focused on thermoplastic CFRP. Journal of the Japan Society for Precision Engineering, 81(6), pp. 489-493, 2015.

[3] Yamane, M., Ohsawa, I., Uzawa, K., Masato, T. \& Takahashi, J., Possibility of repeated recycling of CFRTP for mass production automotive application. Proceedings of 15th European Conference on Composite Materials, pp. 1-8, 2012.

[4] Tanaka, K., Composites for automotive application in Composite Europe 2017. Proceedings of the 9th Symposium on Composite Materials for Automotive Applications, pp. 5-6, 2017.

[5] Harte, A.M. \& McNamara, J.F., Over-injection of thermoplastic composites: I. Processing and testing of components. Journal of Materials Processing Technology, 182, pp. 12-20, 2007.

[6] Tanaka, K., Hirata, A. \& Katayama, T., Continuous fiber reinforced thermoplastics molding by melted thermoplastic-resin transfer molding process. Journal of the Society of Materials Science, 68(8), pp. 628-635, 2019.

[7] Ueda, H., Okumura, W., Emits, H. \& Tanoue, S., Processing of carbon fiber fabric reinforced polycarbonate: The influence of void on the flexural property. Journal of Fiber Science and Technology, 72(12), pp. 258-264, 2016.

[8] Zhu, H., Wu, B., Li, D., Zhang, D. \& Chen, Y., Influence of voids on the tensile performance of carbon/epoxy fabric laminates. Journal of Materials Science and Technology, 27(1), pp. 69-73, 2011. 